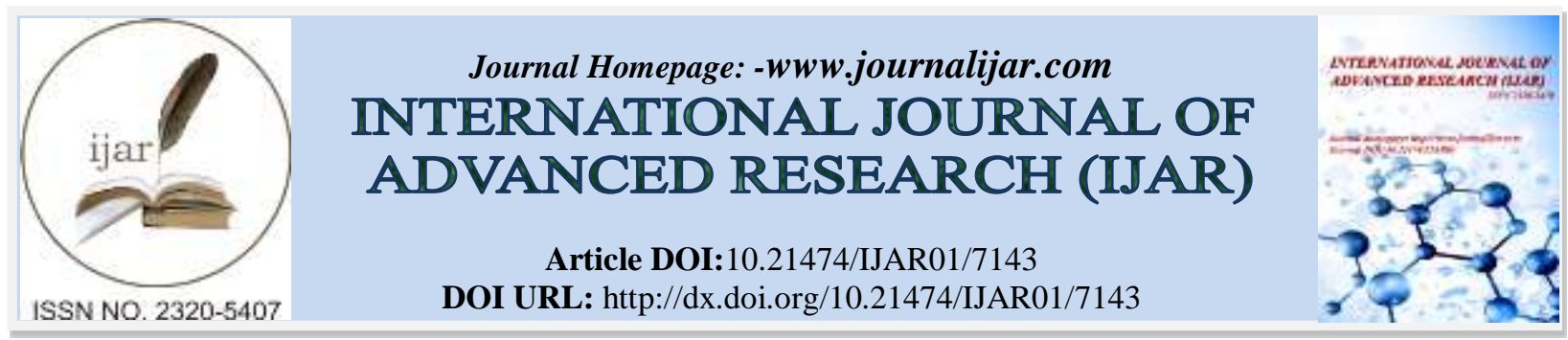

RESEARCH ARTICLE

\title{
CARING FOR A CHILD WITH MULTIPLE DISABILITIES LEADS TO DISTRESS CAUSING BURDEN AMONG PRIMARY CAREGIVERS- AN ANALYSIS.
}

\author{
A. Amala Mary ${ }^{1}$, Rajesh Ramachandran ${ }^{2}$, C. Kayalvizhi ${ }^{3}$ and V. Sree Rajayalakshmi ${ }^{3}$. \\ 1. MSW Scholar, Stella Maris College, Chennai. \\ 2. Rehabilitation Officer, NIEPMD, Chennai. \\ 3. Clinical Supervisor, NIEPMD, Chennai.
}

\section{Manuscript Info}

Manuscript History

Received: 19 March 2018

Final Accepted: 21 April 2018

Published: May 2018

Keywords:-

Caregiver, Caregiver burden, Disability.

\begin{abstract}
The present study undertaken focuses on understanding the causes of caregiver burden (the significant social, physical and emotional burden associated with the lives of caregivers of children with disabilities) among primary caregivers of children with multiple disabilities. The sample selected was $25(\mathrm{~N}=25)$, using random sampling method consisting of primary caregivers (parents $=$ mothers, fathers) of children with multiple disabilities attending National Institute for Empowerment of Persons with Multiple Disabilities (NIEPMD). A self-constructed caregiver burden questionnaire was undertaken using inputs taken from Zarit Burden Interview (ZBI: Zarit, Orr, and Zarit 1985), a BSFCshort/BSFC-s (Elmar Graessel, Hendrik Berth, Thomas Lichte and Hannes Grau), The Caregiver Burden Scale (CBS)(Macera, Eaker, Jannarone, Davis, Stoskopf).The result obtained indicated that there is a notable perceived stress due to caregiving which leads to caregiver's burden, there is an association between the following, gender of the respondents occupational status of the respondents $(\mathrm{p}=0.000, \mathrm{p}<0.5)$, caregivers affected work caregiver burdened $(\mathrm{p}=0.032, \mathrm{p}<0.5)$, physical stress experienced by caregiver affected health of the caregivers $(\mathrm{p}=0.004, \mathrm{p}<0.5)$, caregivers relationship with other family members avoidance of guests, especially close relatives $(\mathrm{p}=0.008, \mathrm{p}<0.5)$, to state a few. The study concludes that caring for a child with disability leads to an increased distress which leads to caregiver burden among primary caregivers. Raising awareness about the disability, providing institutional support such as counselling sessions, day care facilities and other respite care services can enable better caregiving.
\end{abstract}

Copy Right, IJAR, 2018,. All rights reserved.

\section{Introduction:-}

Carers or caregivers are unpaid or paid members providing assistance to other people who on account of physical disability, chronic illnesses or cognitive impairment are unable to perform certain activities on their own. Caring for a child with disability may be challenging, yet rewarding. Parenting a child with special needs may lead to greater decline in the instrumental activities of daily living, which is quite opposite to that of parents with typically 
developing children. Such informal caregiving paves way to significant social, physical and emotional burden associated with the lives of caregivers of disabled children.

The following are the various challenges and problems faced by the primary caregivers, while caring for their children with disabilities. This includes caregiver's health issues, family relationships, financial burden, psychosocial problems, treatment and rehabilitation costs, etc. (Floyd \& Gallagher, 1997). Also, the distress related to caregiving is related to the seriousness of disability (Chan\& Sigafoos, 2001: Cummins, 2001).

Caregiver burden refers to the misfortunes, the caregivers face because of caring for their children with disabilities. Caregiver burden tools focus on the progression of disease of care recipients and its impact on the caregiver's physical, emotional, mental, and psychological status. The present study uses a self-constructed caregiver burden questionnaire which was developed using inputs taken from Zarit Burden Interview (ZBI: Zarit, Orr, and Zarit 1985), a BSFC-short/BSFC-s (Elmar Graessel, Hendrik Berth, Thomas Lichte and Hannes Grau), The Caregiver Burden Scale (CBS) (Macera, Eaker, Jannarone, Davis, Stoskopf).The result obtained indicated that there is a notable perceived stress due to caregiving which leads to caregiver's burden.

\section{Review of Literature:-}

Erikson \&Upshur, (1989) in their study "Caregiver burden is conceptualised as a multidimensional response to physical, psychological, emotional, social, and financial stressors associated with the caregiving experience". Singhi et al (1990) in their study examined the psychosocial problems in parents and families of children with disabilities. The study comprised of fifty families with children having physical disabilities, fifty families of children with mental retardation and fifty families with healthy children. With the use of standardized scale, the social burden, marital adjustment and maternal neuroticism was measured the findings stated greater financial stress, disruption of family leisure and routine, poor social interaction, poor mental and physical health were observed in families which had disabled children. Ray and Ritchie (1993) in their study stated that "Parents described many dimensions of caregiver burden. The results obtained using the clinician overall burden index, coping health inventory and home interviews stated that increasing caregiver burden was associated with greater stressfulness". Mueller (2002), studied the parental and psychological stress with the help of parenting stress index. He stated that higher, than average levels of stress on subscales related to parent-child dysfunctional interaction, raising the difficult child, higher levels of stress related to poorer family adjustments and higher levels of behaviour problems. In the study by Mugno, Ruta, D'Amigo and Mazzano, (2007), "Parents of children with cerebral palsy and mental retardation and parents of normal children were compared with the use of WHOOL-BREQ questionnaire, the quality of life of these parents and the parental burden they faced were assessed. The results suggested that compared with parents of healthy children, parents with persons with disabilities reported impairment in physical activity and social relationship. Parents of such children seem to display a higher level of burden, probably.

\section{Objectives:-}

To examine the factors associated with the subjective caregiver burden in a sample of parents raising a child with multiple disabilities.

\section{Hypothesis:-}

There exists no significant relationship in caring for a child with disability leading to caregiver's burden among primary caregivers.

\section{Methodology:-}

Descriptive study design was adopted for the study as its main goal was to understand the effects of primary caregiver's burden in caring for their children with disabilities. The universe comprises of the primary caregivers of children with disabilities who avail services at NIEPMD. The sample selected was $25(\mathrm{~N}=25)$, consisting of primary caregivers (parents $=$ mothers, fathers) of children with multiple disabilities attending NIEPMD services. The samples were randomly selected using a convenience sampling method. The criteria of selection for the respondents of the study were the primary caregivers of children with multiple disabilities. The tool for data collection includes basic demographic details along with a self-constructed caregiver burden questionnaire. The data collected was analysed by using appropriate statistical tool. 


\section{Results:-}

The participants in this study consisted of 25 parents ( 21 females and 4 male). The mean age of the participants was $36.2(\boldsymbol{\sigma}=4.74$, Range $=22)$

Demographic details:-

Table no 1:-

\begin{tabular}{|c|c|}
\hline Demographic details & $\%$ \\
\hline \multicolumn{2}{|l|}{ Gender } \\
\hline Male & 16.0 \\
\hline Female & 84.0 \\
\hline \multicolumn{2}{|l|}{ Religion } \\
\hline Hindu & 92.0 \\
\hline Muslim & 8.0 \\
\hline \multicolumn{2}{|l|}{ Community } \\
\hline $\mathrm{SC}$ & 44.0 \\
\hline $\mathrm{BC}$ & 28.0 \\
\hline $\mathrm{MBC}$ & 28.0 \\
\hline \multicolumn{2}{|l|}{ Educational qualification } \\
\hline Secondary school & 36.0 \\
\hline Higher secondary school & 16.0 \\
\hline Graduates & 48.0 \\
\hline \multicolumn{2}{|l|}{ Occupational status } \\
\hline Not Employed & 80.0 \\
\hline Self Employed & 4.0 \\
\hline Private Job & 8.0 \\
\hline Government jobs & 8.0 \\
\hline \multicolumn{2}{|l|}{ Income } \\
\hline No Income & 80.0 \\
\hline $5,001-10,000$ & 8.0 \\
\hline $15,001-20000$ & 8.0 \\
\hline Above 20,001 & 4.0 \\
\hline \multicolumn{2}{|l|}{ Family Size } \\
\hline Up to 3 & 20.0 \\
\hline $4-5$ & 72.0 \\
\hline $6 \& 7$ & 8.0 \\
\hline
\end{tabular}

The above table infers to the basic demographic details of the samples. Variables such as age, gender, religion, educational qualification, occupational status, income and family size were studied. The mean age of the study samples was $36.2(\sigma=4.74$, range $=22)$. The percentile of the following variables were obtained, gender $(\mathrm{m}=16 \%$, $\mathrm{f}=84 \%$ ), religion $(\mathrm{Hindu}=92 \%$, Muslim $=8 \%)$, community $(\mathrm{SC}=44 \%, \mathrm{BC}=28 \%, \mathrm{MBC}=28 \%)$, educational qualification (secondary school $=36 \%$, higher secondary school $=16 \%$, college $=48 \%$ ), occupational status(not employed $=80 \%$,self-employed $=4 \%$, private job $=8 \%$, government jobs $=8 \%$ ) income (no income $=80$, 5,001$10,000=8 \%, 15,001-20000=8 \%$, above $20,001=4 \%)$, family size (Up to $3=20 \%, 4-5=72 \%, 6 \& 7=8 \%)$. Many of the mothers sacrificed their jobs in order to support the children and look after the household. In case of better paid jobs, especially government jobs with higher salaries, either of the spouses lets the other one take up the job and stays at home to look after the children. It was also observed that families with more than one child with a disability suffered much more than families which cared for a single disabled child.

The study used a self-constructed caregiver burden questionnaire which was developed using inputs taken from Zarit Burden Interview (ZBI: Zarit, Orr, and Zarit 1985), a BSFC-short/BSFC-s (Elmar Graessel, Hendrik Berth, Thomas Lichte and Hannes Grau), The Caregiver Burden Scale (CBS) (Macera, Eaker, Jannarone, Davis, Stoskopf).The questionnaire was pretested in order to eliminate bias. 


\section{The inclusion criteria for the study:-}

Denotes parents (mothers / fathers of children up to the age of 15 affected with multiple disabilities, attending NIEPMD services) and parents of more than one child affected with multiple disabilities, the study excludes parents (mothers/fathers of children above 15 affected with multiple disabilities, attending NIEPMD services).

\section{Do you feel tired and worn out?}

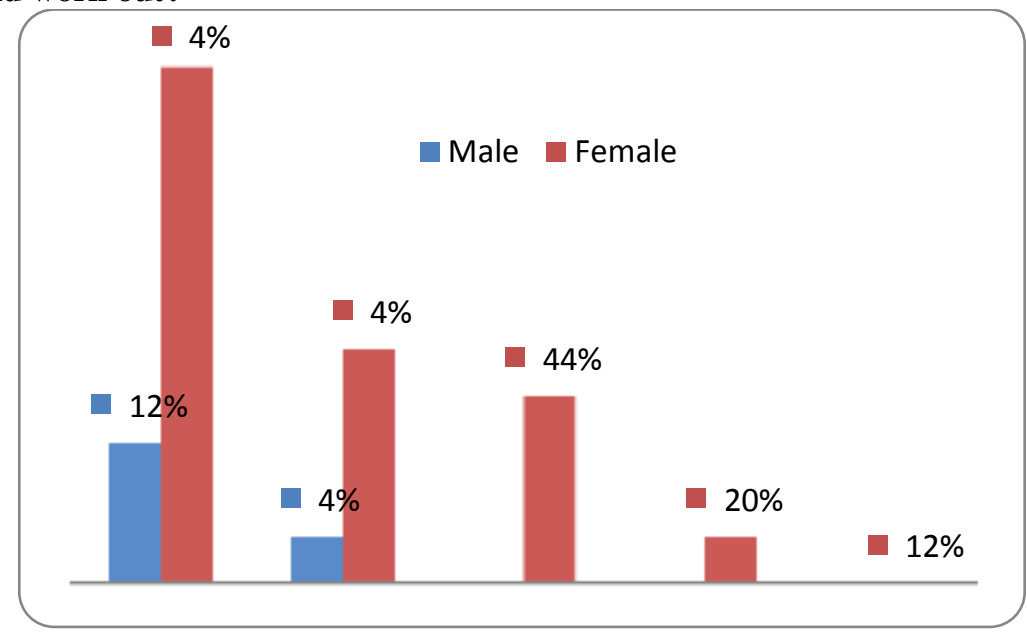

Figure 1:-Tiredness

Figure 1 depicts the tiredness perceived by the primary caregivers, out of $16 \%$ of the male caregivers, $12 \%$ of the male caregivers stated that they never felt tired while caring for their children, another $4 \%$ of the male caregivers stated that they rarely felt tired because of caregiving. Among $84 \%$ of the female caregivers, $4 \%$ of the female caregivers stated that they never felt tired because of caregiving, $4 \%$ of the female caregivers stated that they rarely felt tired because of caregiving, $44 \%$ of the female caregivers stated that they sometimes felt tired because of caregiving. $20 \%$ of the female caregivers stated that they often felt tired because of caregiving and the remaining $12 \%$ of the female caregivers stated that they always felt tired because of caregiving.

\section{Do you find it physically tiring to take care of your child?}

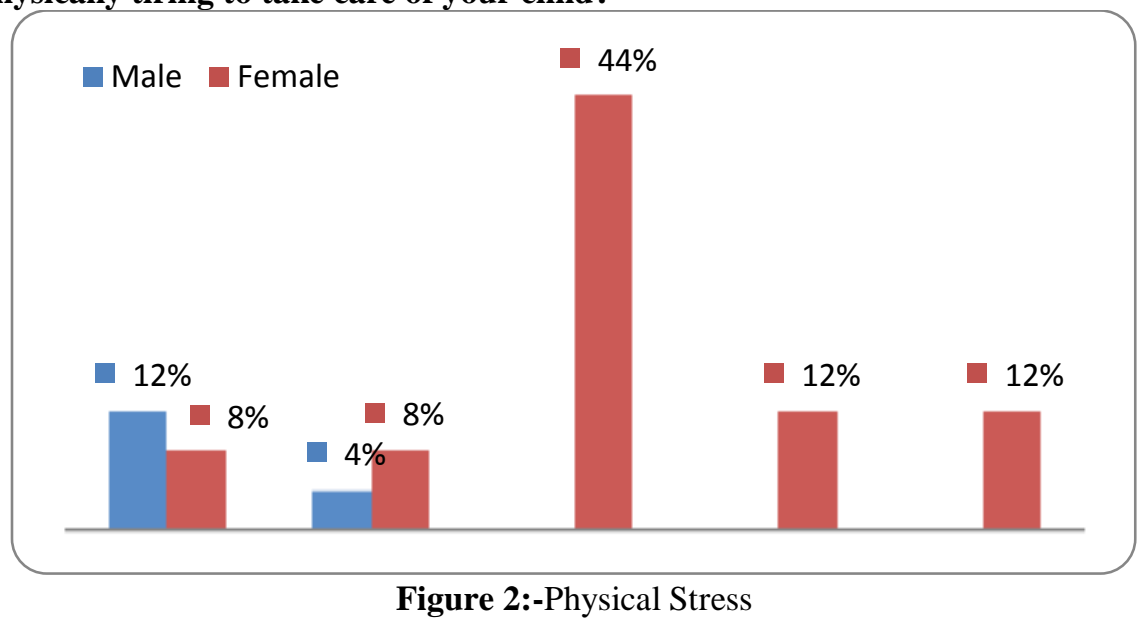

Figure 2 depicts the physical stress perceived by the primary caregivers, out of $16 \%$ of the male caregivers, $12 \%$ of the male caregivers stated that they never felt physically tired in taking care of their children while $4 \%$ of the male caregivers stated that they rarely felt tired while taking care of their children. Among $84 \%$ of the female caregivers, $8 \%$ of the female caregivers stated that they never felt physically tired while caring for their children, $8 \%$ of the female caregivers stated that they rarely felt physically tired while caring for their children, $44 \%$ of the female caregivers stated that they sometimes felt physically tired while caring for their children.12\% of the female 
caregivers stated that they often felt physically tired while caring for their children and another $12 \%$ of the female caregivers stated that they always felt physically tired while caring for their children.

In general, caring for a child with disability may be physically tiring, it is clear that more than the fathers, the mothers feel physically tired because they spent most of their time with their children providing them with all physical necessities and assisting the children in undergoing treatment and rehabilitation. The physical complaints stated by the caregivers are sleep disturbances, physical ailments such as nausea, joint aches, etc caused by long distance travels. Parents who had more than one child with disability were more physically stressed, and those who had little children with disability felt physically tiring. Parents of children with intellectual disability and physical disability were also stressed out. Moreover, it is very hard for those parents who themselves have health issues that needs to be addressed.

\section{Do you feel lonely or isolated because of caregiving?}

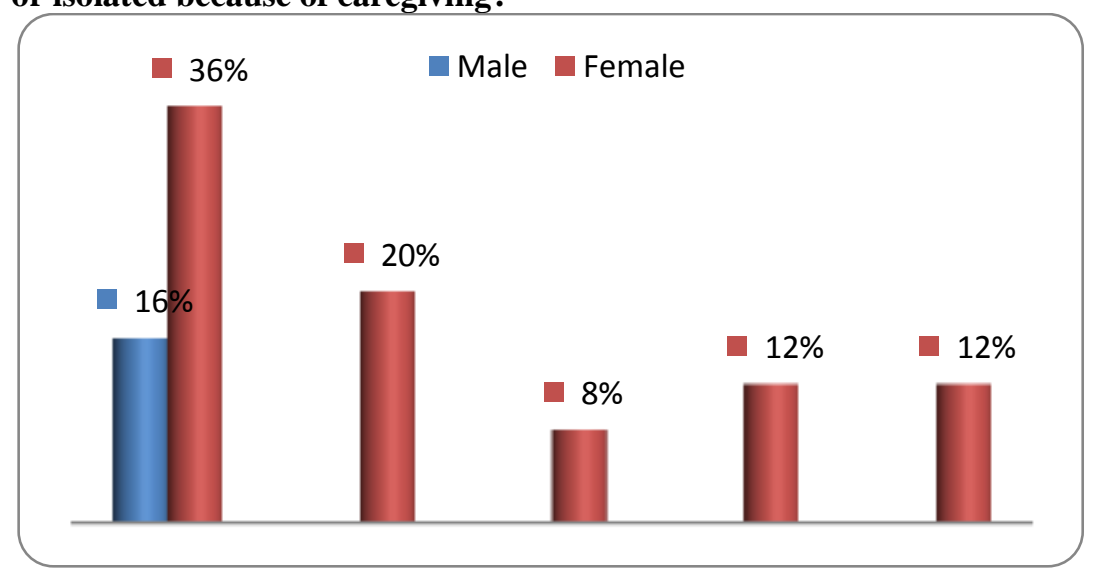

Figure 3:-Feelings of Isolation

Figure 3 depicts the feelings of isolation perceived by the primary caregivers; almost all male caregivers (16\%) stated that they never felt isolated by others while caring for their children. Out of $84 \%$ of the female caregivers, $36 \%$ of the female caregivers stated that they never felt isolated while caring for their children, $20 \%$ of the female caregivers stated that rarely felt isolated while caring for their children, $8 \%$ of the female caregivers stated that they sometimes felt isolated, $12 \%$ of the female caregivers stated that they often felt isolated and another $12 \%$ of the female caregivers stated that they always felt isolated while taking care of their children.

Feeling lonely or isolated is one of the contributing factors of the psychosocial problems faced by the caregivers. Those caretakers who had moral support of their spouse and other family members did not feel lonely or isolated and for those who had to shoulder all the needs of their children and those who did not receive the required help, stated as often and always. Those parents who were not having high coping skills did perceive stigma, also the difference in the levels of stress, depression, anxiety, guilt is not the same for everyone. 
Do you feel that your physical and mental health is affected by caregiving?

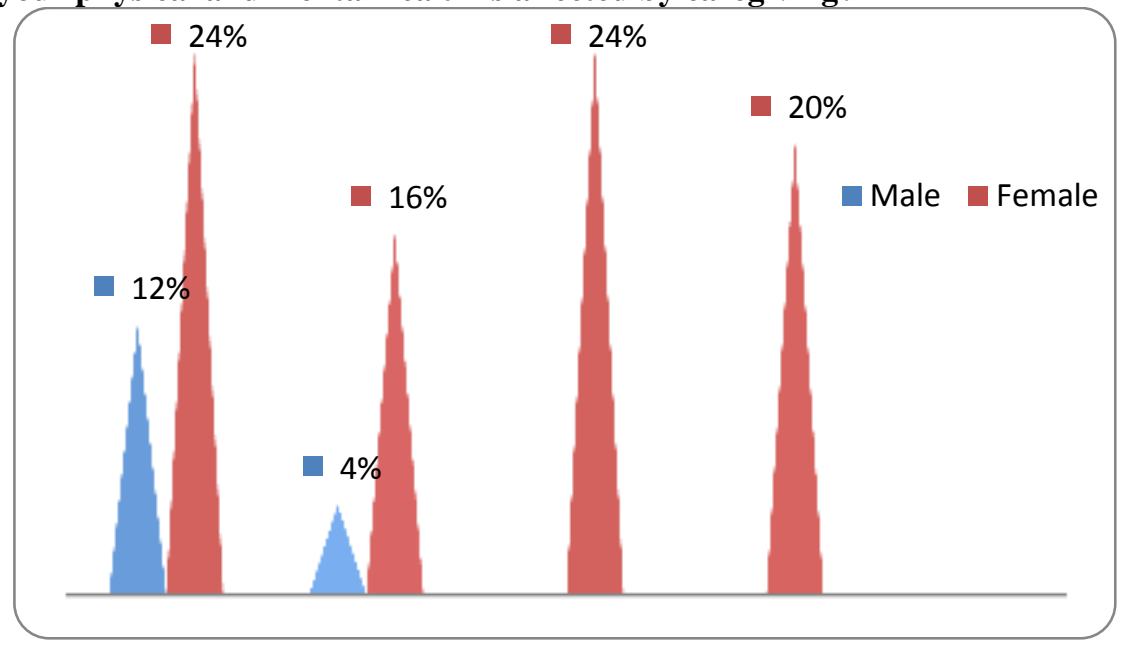

Figure 4:-Affected Physical \&Mental Health

Figure 4 depicts the affected physical and mental health of the primary caregivers, out of $16 \%$ of the male caregivers, $12 \%$ of the male caregivers stated that they never felt that their physical and mental health was affected because of caregiving and the remaining $4 \%$ of the male caregivers stated that their physical and mental health was rarely affected because of caregiving. Among $84 \%$ of the female caregivers, $24 \%$ of the female caregivers stated never, $16 \%$ of the female caregivers stated that they rarely felt that their physical and mental health affected because of caregiving, $24 \%$ of the female caregivers stated that they sometimes felt that their physical and mental health to be affected and another $20 \%$ of the female caregivers stated that their physical and mental health is often affected because of caregiving.

The reason for ill health among parents include loss of moral support from other relatives, loss of institutional support, lack of flexible working hours at workplace, lack of ability to juggle between care and support rendered to the care recipient and other family members, social stigma, fear, feelings of hopelessness and helplessness, anxious of what would happen to the children in the future, etc. This was more seen in parents whose children suffered due to mental retardation and other disabilities, while it was less in those whose children who are able to take care of their daily needs. For example, parents of children with developmental disorder and other learning disabilities were less anxious than those whose children who were physically and mentally retarded.

Do you feel that your relationship with other family members (especially your spouse) have been strained due to care-giving?

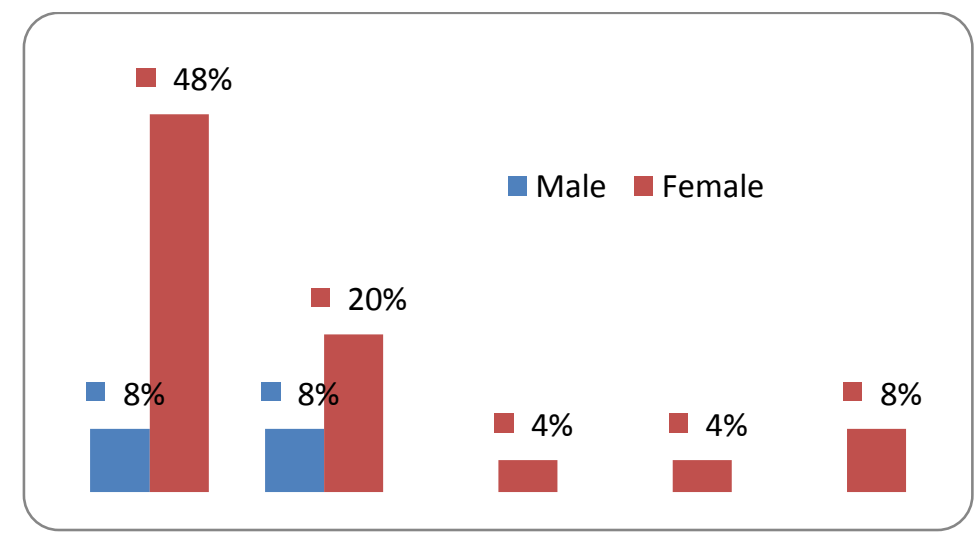

Figure 5:-Strained Spousal \& Other Familial Relationships

Figure 5 depicts the strained spousal and other familial relationships of the primary caregivers, out of $16 \%$ of the male caregivers, $8 \%$ of the male caregivers stated that they have healthy marital relationship as well as healthy relationships with other family members and the remaining $8 \%$ of the male caregivers stated that they rarely felt that 
they had strained marital relationship / strained relationship with other family members due to caregiving. Among $84 \%$ of the female caregivers, $48 \%$ of the female caregivers stated that they never had strained marital relationship or strained familial relationships due to caregiving, $20 \%$ of the female caregivers stated they rarely felt they had a strained relationship with the spouse or other family members. $4 \%$ of the population stated that they sometimes felt that their relationship with the spouse and other family members is strained, $4 \%$ of the population stated often and the remaining $8 \%$ of the population stated that their relationship with the spouse and other family members is strained.

The reasons for having strained marital or other familial relationships are due to the following factors: lack of understanding from either one or both sides, the unwillingness of the other member to step in and shoulder the responsibilities in caring for children with disability. In case of siblings who were not mature to understand, etc.

Do you feel that you are being held responsible for your child's disorder/disability?

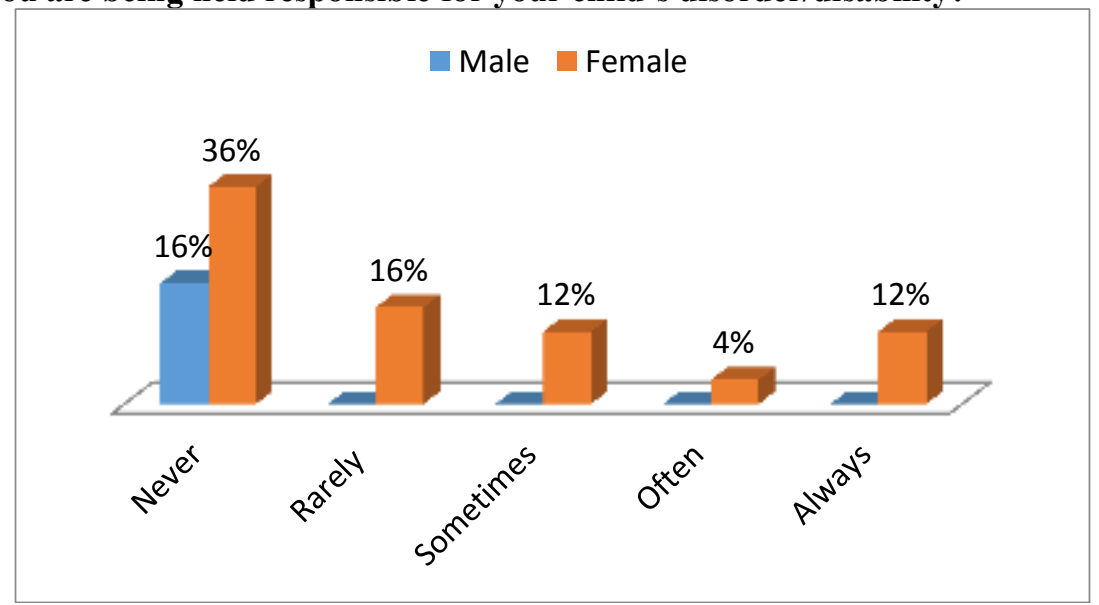

Figure 6:-Guilt

Figure 6 depicts the guilt perceived by the primary caregivers; almost all male caregivers (16\%) were not chided for the child's disability. Among $84 \%$ of the female caregivers, $36 \%$ of the female caregivers stated that they were never held responsible for the child's condition. $16 \%$ of the female caregivers stated that were very rarely associated responsible for the child's condition, $12 \%$ of the female caregivers stated sometimes and $4 \%$ of the female caregivers stated that they were often held responsible for their child's condition and the remaining $12 \%$ of the female caregivers stated that they were always held responsible for the child's condition.

The reasons for associating guilt with the child's disability especially with the mothers are due to personal differences, lack of knowledge about causes of disability, false social beliefs, etc. There were no traces of selfstigma.

Do you avoid inviting friends, acquaintances home because of your child's disability?

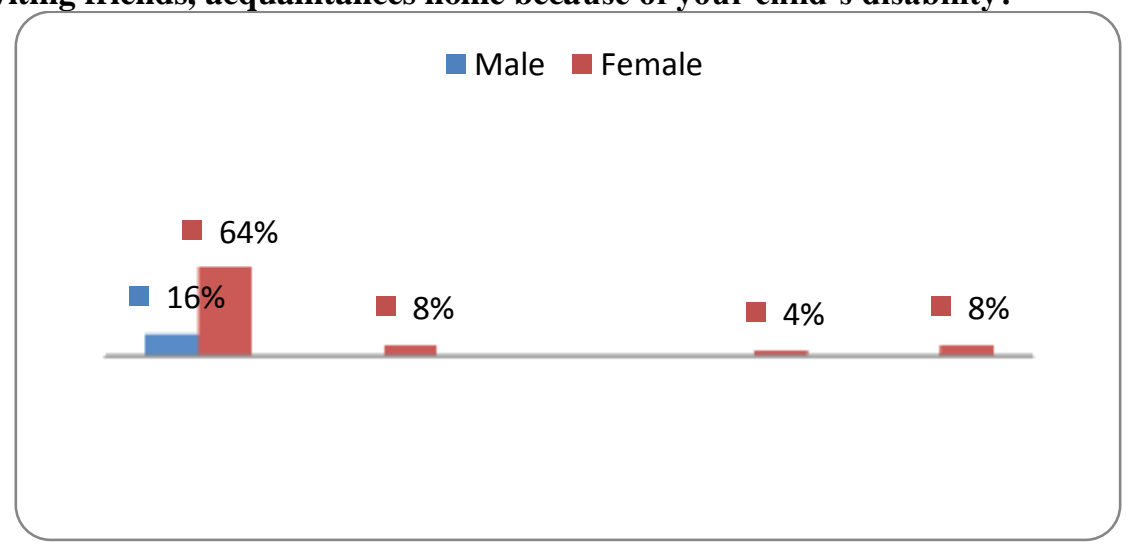

Figure 7:-Avoidance of Guests 
Figure 7 depicts the avoidance of guests due to child's disability/disorder; almost all male caregivers (16\%) stated they never had a second thought while inviting guests. Among $84 \%$ of the female caregivers, $64 \%$ of the female caregivers stated that they never stopped inviting friends and acquaintances to their home, $8 \%$ of the female caregivers stated that rarely avoided inviting friends and acquaintances to their home. $4 \%$ of the female caregivers stated they often avoided friends and acquaintances and the remaining $8 \%$ of the population stated that they always avoided friends and acquaintances.

The reasons for not inviting friends and acquaintances home include social stigma, perceived stigma by the parents as well as the family members.

\section{Do you feel that you are overburdened with caregiving?}

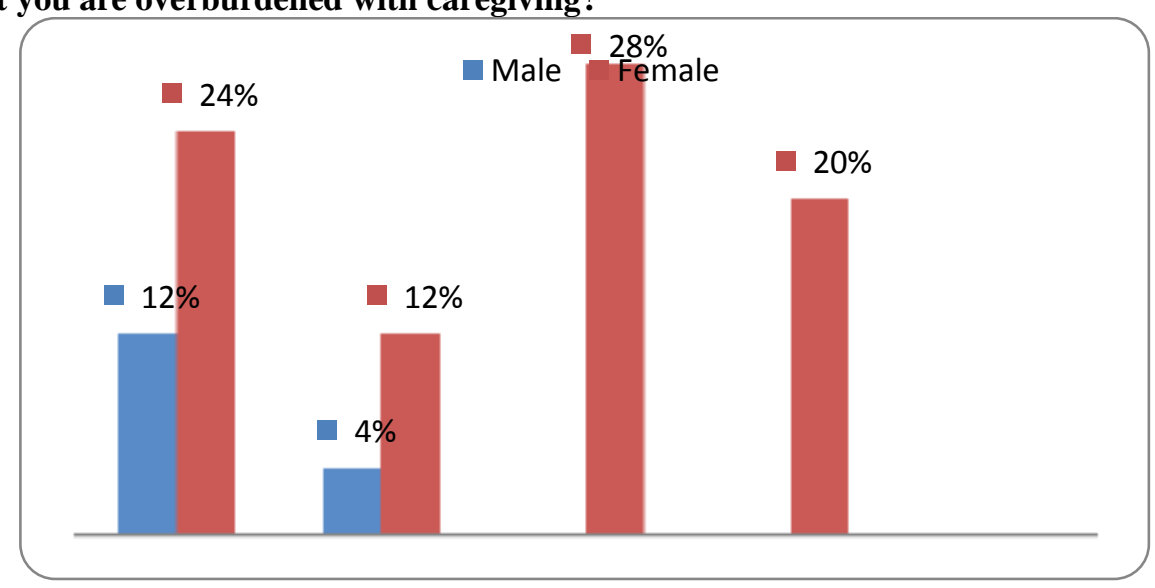

Figure 8:-Overburdened

Figure 8 depicts the caregiver being overburdened with child's responsibility, out of $16 \%$ of the male caregivers, $12 \%$ of the male caregivers stated that they never felt overburdened with caregiving. $4 \%$ of the male caregivers stated that they rarely felt burdened with caregiving. Among $84 \%$ of the female caregivers, $24 \%$ of the female caregivers stated that they never felt burdened with caregiving, $12 \%$ of the female caregivers stated that they rarely felt they never felt burdened with caregiving. $28 \%$ of the female caregivers stated that they sometimes felt burdened with caregiving and $20 \%$ of the female caregivers stated that they often felt burdened with caregiving.

Do you feel that your personal space is lost?

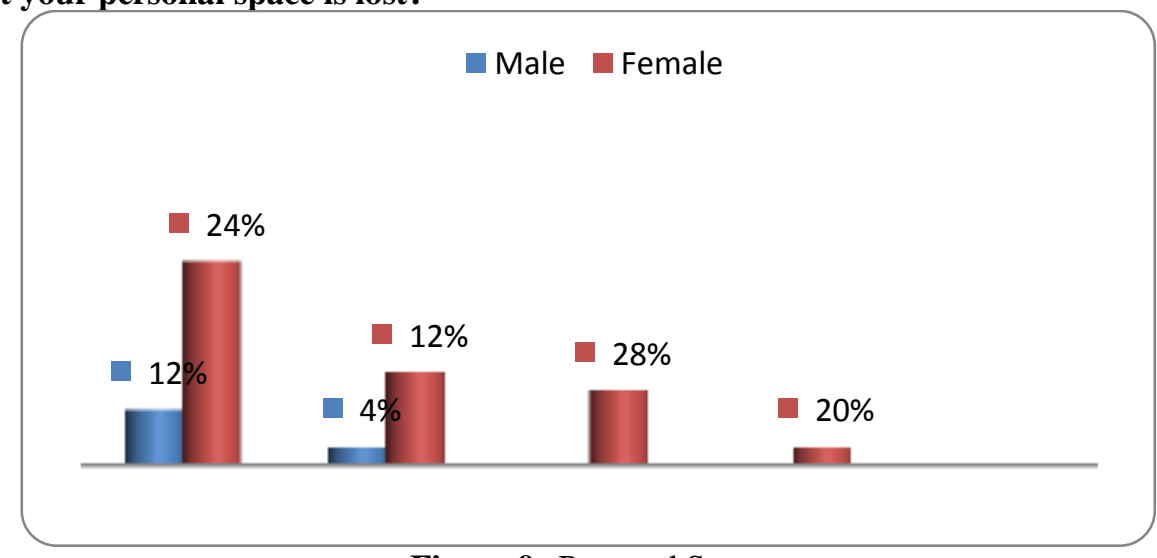

Figure 9:-Personal Space

Figure 9 depicts the loss of personal space perceived by the primary caregivers, out of $16 \%$ of the male caregivers, $12 \%$ of the male caregivers stated that they never felt they had lost their personal space due to caregiving, $4 \%$ of the male caregivers stated they rarely felt they lacked personal space. Among $84 \%$ of the female caregivers, $24 \%$ of the female caregivers stated that they never felt that they had lost their personal space, $12 \%$ of the female caregivers 
stated that they rarely lacked personal space. $28 \%$ of the female caregivers stated sometimes they lacked personal space and $20 \%$ of the female caregivers stated that they often lacked personal space.

The reasons for lack of personal space are that the parents felt that they should give most of their time for better caregiving. The caregivers do not understand the fact that their health and wellbeing is essential for effective caregiving.

Do you feel that you often get the required assistance for caregiving from your family members?

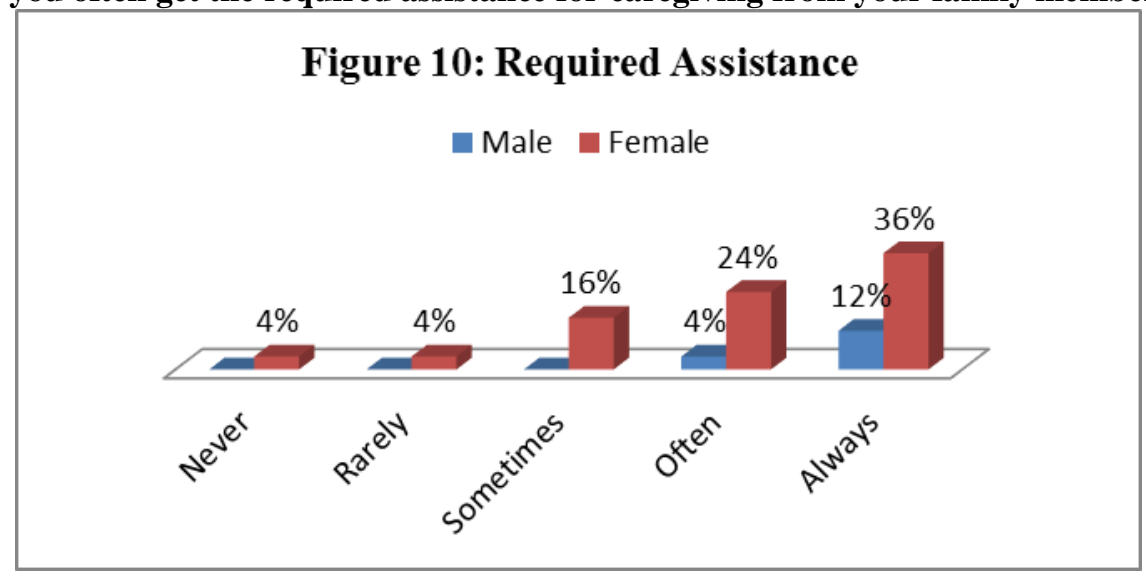

Figure 10 depicts the range of required assistance received by the primary caregivers, out of $16 \%$ of the male caregivers, $4 \%$ of the male caregivers stated that they often received the required assistance for caregiving and another $12 \%$ of the male caregivers stated that they always received the required assistance for caregiving. Among $84 \%$ of the female caregivers, $4 \%$ of the female caregivers stated that they never received the required assistance for caregiving, $4 \%$ of the female caregivers stated that they rarely received the required assistance. $16 \%$ of the female caregivers stated that they sometimes received the required assistance for caregiving, $24 \%$ of the female caregivers stated that they often received the required assistance for caregiving and the remaining $36 \%$ of the female caregivers stated that they always received the required assistance for caregiving.

\section{Do you feel that you are economically dependent on others for caregiving?}

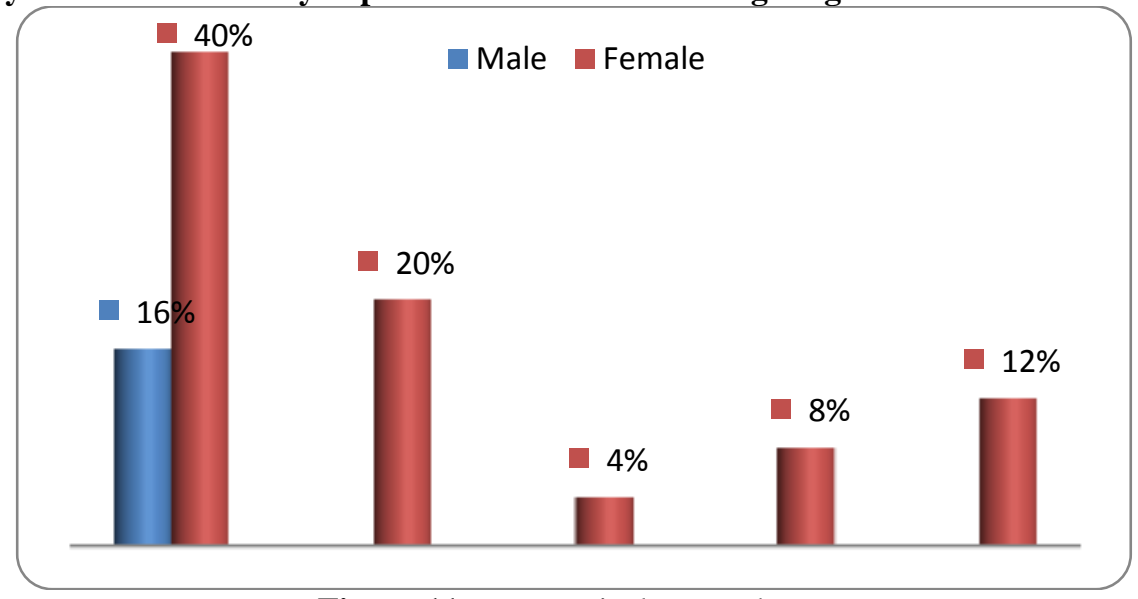

Figure 11:-Economical Dependency

Figure 11 depicts the economical dependency of the primary caregivers; almost all male caregivers (16\%) stated that they never felt economically dependent on others for caregiving. Among $84 \%$ of the female caregivers, $40 \%$ of the female caregivers stated that they never felt economically dependent on others for caregiving, $20 \%$ of the female caregivers stated that they rarely felt economically dependent on others for caregiving. $4 \%$ of the female caregivers stated that they sometimes felt economically dependent on others for caregiving. $8 \%$ of the female caregivers stated 
that they often felt economically dependent on others for caregiving and the remaining $12 \%$ of the female caregivers stated that they were always economically dependent on others for caregiving.

Economical dependency is seen among mothers more often as they were the unemployed persons in the family. Families which have more than one employed person were able to meet the expenditures while those which had only one working member were not able to meet the expenses.

Do you feel that your work gets affected because of caregiving?

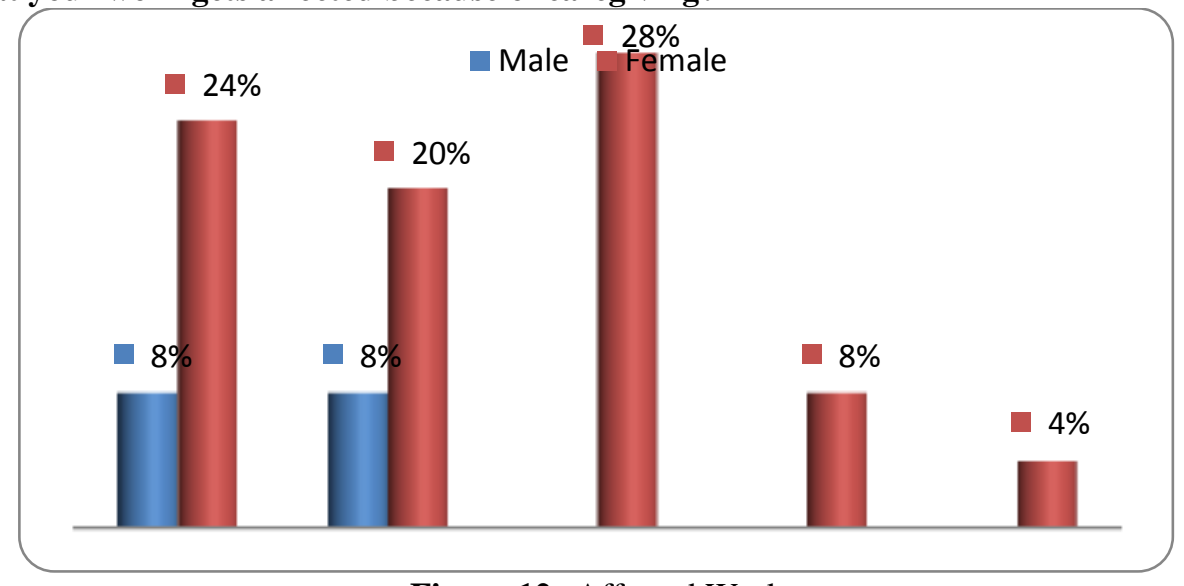

Figure 12:-Affected Work

Figure 12 depicts the affected work of primary caregivers due to caregiving, out of $16 \%$ of the male caregivers, $8 \%$ of the male caregivers stated that they never felt that their other works were affected because of caregiving and another $8 \%$ of the male caregivers stated that they rarely felt that their work was affected because of caregiving. Among $84 \%$ of the female caregivers, $24 \%$ of the female caregivers stated that they never felt that their other works were affected because of caregiving, $20 \%$ of the female caregivers stated that their works were rarely affected because of caregiving, $28 \%$ of the female caregivers stated that they sometimes feel that their works were affected because of caregiving. $8 \%$ of the female caregivers stated that their works were often affected because of caregiving and another $4 \%$ of the female caregivers stated that their works were always affected because of caregiving.

More than fathers, mothers felt that their works were affected as they perform the reproductive roles such as caring for the other family members, looking after the sick, prioritizing household chores, etc. This is the reason why most of the educated mothers though they wished to work could not do so, because of the role of providing extra care for their children and looking after the household responsibilities. They even quit their jobs in order to provide the best care.

Had you expected life to be different than it is at your age?

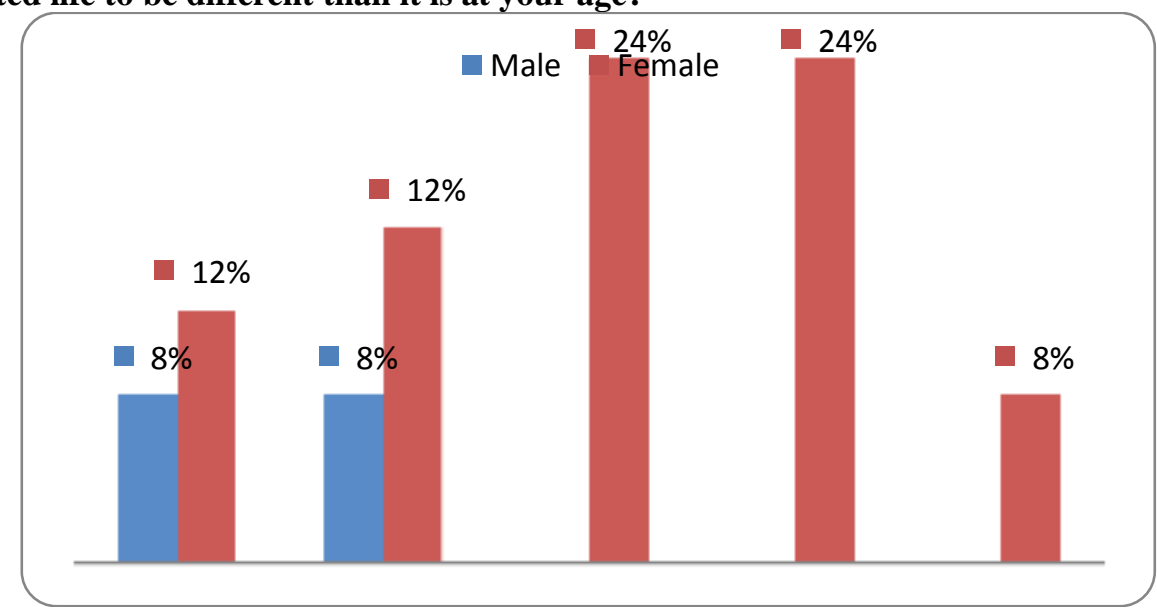

Figure 13:-Expected Life 
Figure 13 depicts the expected life as perceived by the primary caregivers, out of $16 \%$ of the male caregivers, $8 \%$ of the male caregivers stated that they never expected a better life and $8 \%$ of the male caregivers stated that they rarely expected a better life. Among $84 \%$ of the female caregivers, $12 \%$ of the female caregivers stated that they never expected a better life, $16 \%$ of the female caregivers stated that they rarely expected a better life, $24 \%$ of the female caregivers stated that they often expected a better life and another $8 \%$ of the female caregivers stated that they always expected a better life.

All of the above primary caregivers, though they accepted the fact that they were happy with the present situation, felt that it would have been much better if the child's disability disappeared. Seeing the child suffering is the most difficult part for the parents.

Do you feel that you could do much better in caring for your child?

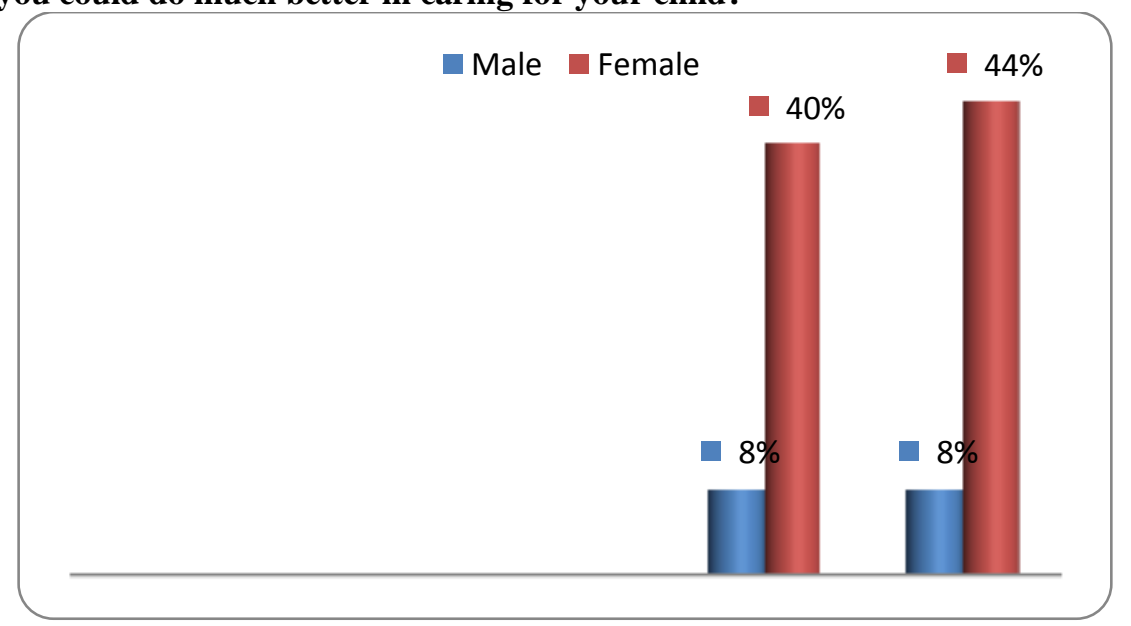

Figure 14:-Interested in Better Caregiving

Figure 14 depicts the interest of the primary caregivers in providing a better care to their children, out of $16 \%$ of the male caregivers, $8 \%$ of the male caregivers stated that they often felt to improve caregiving, and the remaining $8 \%$ of the male caregivers stated that they always felt to improve their caregiving process. Among $84 \%$ of the female caregivers, $40 \%$ of the female caregivers stated that they often felt to improve their caregiving process and the remaining $44 \%$ of the female caregivers stated that they always felt to improve their caregiving process.

It is found out that all of the above primary caregivers wanted to improve their caregiving process. Access to disability related knowledge and social support would help them achieve their targets.

Overall, do you feel burdened in caring for your child?

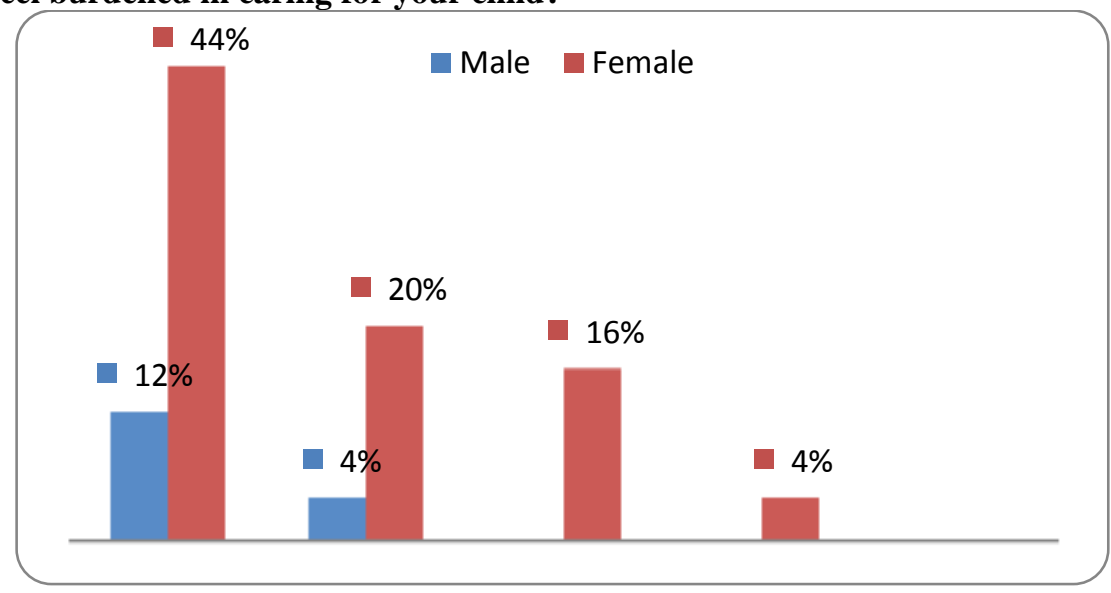

Figure 15:-Burdened 
Figure 15, depicts the burden experienced by primary caregivers, out of $16 \%$ of the male caregivers, $12 \%$ of the male caregivers stated that they never felt burdened due to caregiving, and the remaining $4 \%$ of the male caregivers stated that they rarely felt burdened due to caregiving. Among $84 \%$ of the female caregivers, $44 \%$ of the female caregivers, they felt that they were never burdened due to caregiving. $20 \%$ of the female caregivers stated that they rarely felt burdened due to caregiving. $16 \%$ of the male caregivers stated that they were sometimes burdened due to caregiving and the remaining $4 \%$ of the female caregivers stated that they were often burdened due to caregiving.

Chi-square test was used to test the association between the variables.

Gender of the respondents ${ }^{\wedge}($ Expected life) as stated by the respondents:-

\begin{tabular}{|l|c|c|c|}
\hline $\begin{array}{l}\text { Gender of the respondents^ (Expected life) as } \\
\text { stated by the respondents }\end{array}$ & Value & df & Asymp. Sig. (2-sided) \\
\hline Pearson Chi-Square & $9.561^{\mathrm{a}}$ & 4 & .049 \\
\hline Likelihood Ratio & 9.225 & 4 & .056 \\
\hline Linear-by-Linear Association & .864 & 1 & .353 \\
\hline N of Valid Cases & 25 & & \\
\hline
\end{tabular}

Since the $p$-value $(0.049)$ is less than the standard value $a=0.5$, we can reject the null hypothesis and conclude that there is an association between the gender of the respondents and their response to expected life.

Gender of the respondents ${ }^{\wedge}$ Occupational status of the respondents:-

\begin{tabular}{|l|c|c|c|}
\hline $\begin{array}{l}\text { Gender of the respondents } \\
\text { status of the respondents }\end{array}$ & Value & df & Asymp. Sig. (2-sided) \\
\hline Pearson Chi-Square & $17.932^{\mathrm{a}}$ & 3 & .000 \\
\hline Likelihood Ratio & 14.043 & 3 & .003 \\
\hline Linear-by-Linear Association & 3.384 & 1 & .066 \\
\hline N of Valid Cases & 25 & & \\
\hline
\end{tabular}

Since the $p$-value $(0.000)$ is less than the standard value $a=0.5$. We can reject the null hypothesis and conclude that there is an association between the gender of the respondents and the occupational status of the respondents. Female respondents stayed back in order to provide the needed care and support to their children yet the remaining went to jobs because they were better paid than the other. Among male respondents, most of them went to jobs and a very few remained back home because of low income than the other spouse.

Caregivers affected work ${ }^{\wedge}$ Caregiver burdened:-

\begin{tabular}{|l|c|c|c|}
\hline $\begin{array}{l}\text { Caregivers affected work } \\
\text { burdened }\end{array}$ & Value & df & Asymp. Sig. (2-sided) \\
\hline Pearson Chi-Square & $27.965^{\mathrm{a}}$ & 16 & .032 \\
\hline Likelihood Ratio & 26.957 & 16 & .042 \\
\hline Linear-by-Linear Association & 9.338 & 1 & .002 \\
\hline N of Valid Cases & 25 & & \\
\hline
\end{tabular}

Since the $p$-value (0.032) is less than the standard value $a=0.5$. We can reject the null hypothesis and conclude that there is an association between the caregivers work affected due to caregiving and burden perceived by caregivers. The parents put in lots of efforts to manage between many responsibilities (caring for the primary and secondary care recipients), any inconvenience in performing the defined roles lead to distressed caregiving which leads to caregiver burden.

Physical Stress Experienced by Caregiver ${ }^{\wedge}$ Affected Health of the Caregivers:-

\begin{tabular}{|l|c|c|c|}
\hline $\begin{array}{l}\text { Physical Stress Experienced by Caregiver }{ }^{\wedge} \\
\text { Affected Health of the Caregivers }\end{array}$ & Value & df & Asymp. Sig. (2-sided) \\
\hline Pearson Chi-Square & $34.857^{\text {a }}$ & 16 & .004 \\
\hline Likelihood Ratio & 34.304 & 16 & .005 \\
\hline Linear-by-Linear Association & 11.070 & 1 & .001 \\
\hline N of Valid Cases & 25 & & \\
\hline
\end{tabular}


Since the $\mathrm{p}$-value (0.004) is less than the standard value $\mathrm{a}=0.5$. We can reject the null hypothesis and conclude that there is an association between physical stresses perceived by the caregiver which leads to deteriorating health of the parents. This is because parents spend most of the time in looking after the care recipient that they are least bothered about their health or there are no means to take care of their health which may include lack of financial ability or means to do the same as much of the money is spent for treatment costs and other family expenditures.

Caregivers relationship with other family members ^^ Avoidance of guests, especially close relatives:-

\begin{tabular}{|l|c|c|c|}
\hline $\begin{array}{l}\text { Caregivers relationship with other family } \\
\text { members } \wedge \text { Avoidance of guests, } \\
\text { especially close relatives }\end{array}$ & Value & $\mathrm{df}$ & Asymp. Sig. (2-sided) \\
\hline Pearson Chi-Square & $31.469^{\mathrm{a}}$ & 15 & .008 \\
\hline Likelihood Ratio & 20.028 & 15 & .171 \\
\hline Linear-by-Linear Association & .663 & 1 & .415 \\
\hline N of Valid Cases & 25 & & \\
\hline
\end{tabular}

Since the $\mathrm{p}$-value (0.008) is less than the standard value $\mathrm{a}=0.5$. We can reject the null hypothesis and conclude that there is an association betweencaregiver's relationship with other family members and avoidance of guests, especially close relatives. Few respondents stated that even their own family members sometimes ostracize them due to the child's disability. The flow of communication has been reduced on account of the same.

\section{Conclusion:-}

The study concludes that caring for a child with disability leads to an increased distress which might lead to caregiver burden among primary caregivers. The result obtained indicated that there is a notable perceived stress due to caregiving which leads to caregiver's burden, there is an association between the following variables, gender of the respondents ${ }^{\wedge}$ occupational status of the respondents $(\mathrm{p}<0.001)$, caregivers affected work ${ }^{\wedge}$ caregiver burdened $(\mathrm{p}=0.032, \mathrm{p}<0.5)$, physical stress experienced by caregiver $\wedge$ affected health of the caregivers $(\mathrm{p}=0.004$, $\mathrm{p}<0.5)$,caregivers relationship with other family members ${ }^{\wedge}$ avoidance of guests, especially close relatives $(\mathrm{p}=0.008$, $\mathrm{p}<0.5$ ), to state a few. The study recommends the following for better caregiving: raising awareness about the disability may promote parents to access the available services to get the required social support, institutional support such as counselling sessions, day care facilities and other respite care services can enable these. To help those parents who already feel stressed and depressed, there should be research on developing programs to help improve support group experience and use.

\section{Demerits:-}

Some of the findings of the study state that there is a gender bias in caring for a child with special needs. It would have been nice to have more men participate with the study so we could get a better understanding of how they perceive caregiver burden. Most people probably do not want to admit that they feel stigmatized against and therefore may lie about it (it would have been more accurate if the questionnaire was taken up in a very conducive environment, probably at home).

\section{Recommendations:-}

Future studies are recommended in larger samples and aims to have more men participate in order to get a better understanding of how they perceive caregiver burden. The studies can be based on more specific disabilities for deeper understanding of caregiver's burden.

\section{Acknowledgement:-}

The authors would like to thank the Director of National Institute of Empowerment of Persons with Multiple Disabilities for the support received. The research scholar also wishes to express their appreciation to all the parents who were part of the research.

There was no financial assistance received for the research; it is purely for an academic purpose. 


\section{Reference:-}

1. Chan, J.B., \& Sigafoos, J. (2000). A review of child and family characteristics related to the use of Respite care in developmental disability services. Child \& Youth Care Forum, 29, 27-37. https://link.springer.com. (Accessed online on 20 May 2018)

2. Cummins, R.A., (2001). The subjective wellbeing of people caring for a family member with a severe disability at home. Journal of Intellectual \& Developmental Disability, 26(1), 83-100. https://www.tandfonline.com/ doi/abs/10.1080/13668250020032787. Accessed online on 19th May 2018.

3. Erickson, M., Upshur CC. Caretaking burden and social support: comparison of mothers of infants with and without disabilities. Am J Ment Retard 1989 Nov; 94(3):2508.https://www.ncbi.nlm.nih.gov/m/pubmed/2478171. Accessed online on 20 May 2018.

4. Floyd. F, Gallagher. E.M, Parental Stress, Care Demands, and Use for School-Age Children with Disabilities and Behaviour $\quad$ Problems. $1997 \quad$ Oct; $46(4): 359$. :https://www.jstor.org/stable/585096?seq=1\#page_scan_tab_contents. Accessed online on $19^{\text {th }}$ May 2018.

5. Graessel, E., et al, 2014: Subjective caregiver burden: validity of the 10-item short-version of the Burden Scale for Family Caregivers BSFC-s. In: BMC Geriatrics. 14,S.23:https://www.ncbi.nim.nih.gov/m/pubmed/24555474\&hl=en-IN. Accessed online on $20^{\text {th }}$ May 2018.

6. Macera, C.A., Eaker, E.D., Jannarone R.J., Davis, D.R., Stoskopf, C.H, 1993. A Measure of Perceived Burden among Caregivers. Evaluation \& the Health Professions 16(2), 204-211. https://www.ncbi.nlm.nih.gov/pubmed/10171430. Accessed on 20th May 2018.

7. Mueller, et al. Psychological Stress in Adoptive Parents of Special - Needs Children. Child Welfare, Mar/Apr 2002, Vol.81 Issue, p151-171.21p.2.: https://www.ncbi.nlm.nih.gov/m/pubmed/12014464. Accessed online on $20^{\text {th }}$ May 2018.

8. The World Health Organization Quality of Life Assessment (WHOQOL): development and general psychometric properties. Soc Sci Med. 46(12):156985:https://www.ncbi.nlm.nih.gov/m/pubmed/9672396.(Accessed online on $20^{\text {th }}$ may 2018)

9. Ray .L.D., Ritchie. J.A., 1993.Caring for chronically ill children at home: factors that influence parents'coping.https://www.ncbi.nlm.nih.gov/pubmed/8410642/. (Accessed online 4 June 2018)

10. Zarit, S.H., Orr, N., \& Zarit, J.M. 1985. The Hidden Victims of Alzheimer's disease: Families under stress. https://books.google.co.in/ (accessed online on $19^{\text {th }}$ May 2008). 